\title{
Mineral intake and blood pressure control of Brazilian elderly
}

\begin{abstract}
The aim of this study was to evaluate mineral intake by hypertensive elderly Brazilian patients. The study included 37 patients aged 80 years or more undergoing outpatient follow-up. The dietary intake of calcium, iron, potassium and sodium was assessed by calculating three 24-hour recall, collected on non-consecutive days, including one weekend day. The mineral intake was analyzed according to the recommendations of the Institute of Medicine (IOM) and its adequacy or inadequacy were evaluated by sex and control of systolic and diastolic blood pressure. The sample was characterized by low schooling and per capita income. It was identified a high prevalence of inadequacy for calcium intake $(97.30 \%)$. None of the individuals reached the adequate intake for potassium. The majority of the elderly had adequate iron intake $(69.23 \%)$ and few exceeded the tolerable upper intake level for sodium $(22.22 \%)$. There were no statistically significant differences in the adequacy of mineral intake as to gender and blood pressure control. The majority of the elderly had controlled blood pressure values. The low consumption of calcium and potassium indicates the need of actions of incentive to a diversified feeding, with greater presence of dairy foods, fruits and vegetables.
\end{abstract}

Keywords: hypertension, dietary minerals, aged 80 and over
Volume I Issue 4 - 2017

\author{
Natalia Lobato da Silva,' Samantha Pereira \\ Araújo, ${ }^{2}$ \\ 'School of Social Sciences and Health of the Pontifical Catholic \\ University of Goiás, Brazil \\ ${ }^{2}$ Hypertension League of Federal University of Goiás, Brazil
}

Correspondence: Samantha Pereira Araújo, Hypertension League of Federal University of Goiás, Goiânia, Goiás, Brazil,Tel +55 (62) 984026062, Email samanthaaraujo@hotmail.com

Received: March 22, 2017 | Published: June 06, 2017
Abbreviations: NCD, chronic noncommunicable diseases; $\mathrm{EAR}$, estimated average requirement; AI, adequate intake; UL, maximum tolerable upper intake level; SBP, systolic blood pressure; DBP, diastolic blood pressure

\section{Introduction}

Brazil is going through a demographic transition which results in the rapid aging of the population. ${ }^{1,2}$ The Brazilian population with more than 80 years, was approximately 731,350 inhabitants in year 2000 , and increased to $1,133,223$ in $2010 .{ }^{3}$ Changes due to aging make people more vulnerable to disease development, with an emphasis on chronic noncommunicable diseases (NCDs). ${ }^{4}$ The current food pattern also contributes to the increased incidence of NCDs. The growth in the consumption of ultraprocessed foods results in a greater intake of calories, fats, sugars and sodium, nutrients closely related to diseases such as obesity and hypertension.

Micronutrient intake among Brazilian elderly is far from the recommended values, in consequence of the low variety of foods in the $\operatorname{diet}^{6}$ and low consumption of fruits and vegetables. ${ }^{5}$ The Brazilian population consumes approximately a quarter of the value recommended by the Brazilian Food Guide ${ }^{7}$ for these foods. ${ }^{8}$ Although necessary in relatively small amounts, minerals are involved in the regulation of physiological processes, such as reproduction, immune response, metabolism and neural functions. Minerals must be obtained through food and inadequate consumption can lead to serious damage to health, increasing morbidity and mortality. ${ }^{9}$

High sodium intake has a correlation with NCDs, including hypertension, ${ }^{10}$ which is one of the most prevalent diseases among the elderly. ${ }^{11,12}$ Inadequate intake of calcium and potassium may also contribute to the elevation of pressure levels. ${ }^{13-15}$ Among Brazilians aged 75 or over, the proportion of hypertensive patients is $55 \%{ }^{16,17}$ As for iron deficiency, in addition to causing anemia, it can still lead to a decrease in cognitive abilities in the elderly. ${ }^{18}$ Individuals with reduced cognitive abilities may have lower adherence to medications, including antihypertensive drugs. ${ }^{19}$ The aim of this study was to investigate the consumption of minerals by very elderly hypertensive individuals, in outpatient follow-up.

\section{Materials and methods}

The study target population consisted of patients aged 80 and over who were under regular treatment at a public reference center for the treatment of hypertension. A specific questionnaire was applied for the collection of sociodemographic and lifestyle data. The dietary intake of iron, sodium, calcium and potassium was evaluated by calculating three 24-hour recall, collected on non-consecutive days, including one weekend with Dietwin software professional version. The mineral content of the diet was analyzed according to the recommendations of the Institute of Medicine (IOM). To estimate the prevalence of inadequacy in mineral consumption, the estimated average requirement (EAR) values were taken into account. ${ }^{20,21}$ In the case of potassium, where there is no established EAR, the adequate intake $(\mathrm{AI})^{13}$ was used. Sodium had as reference the maximum tolerable upper intake level (UL). ${ }^{13}$ Blood pressure measurements followed the technique presented by Brazilian Society of Cardiology. ${ }^{22}$ The values obtained were classified according to cutoff points for the elderly aged 80 or older. $^{23}$

Descriptive analyses of the data was performed and presented as means \pm standard deviations. Fisher's exact test was performed to access the difference between minerals intake by gender and blood pressure control. The analyses were performed using Statistical Package for Social Sciences software (version 21 for Windows, SPSS Inc., Chicago, IL, USA). The study was approved by the Research Ethics Committee of the Institution (Protocol No. 700.942 from 06/26/2014). The participants signed informed consent forms. 


\section{Results and discussion}

The sample included 37 hipertensive elderls aged over 80 years, 28 women $(75,68 \%)$ and nine men. The mean per capita income was USD 270.65 and two years of escolarity. The mean daily intake of Table I Minerals intake of very elderly hypertensive patients $(n=37)$ calcium $(443.20 \mathrm{mg})$ and potassium $(1788.61 \mathrm{mg})$ of the elderly were less than half of the recommended values. The minimum calcium intake was only $98.41 \mathrm{mg}$, compared to the recommended $1000 \mathrm{mg}$ (Table 1).

\begin{tabular}{|c|c|c|c|c|}
\hline Minerals & Mean士SD & Minimum & Maximum & Reference values \\
\hline Calcium (mg) & $443,20 \pm 254,37$ & 98,41 & 1361,34 & $1000 \dagger$ \\
\hline \multirow[t]{2}{*}{ Iron (mg) } & $7,21 \pm 3,10$ & 3,10 & 19,89 & Men:6† \\
\hline & & & & Women:5† \\
\hline Potassium (mg) & $|788,6| \pm 523,77$ & 810,53 & $35 \mid 2,54$ & $4700 \ddagger$ \\
\hline Sodium (mg) & $1387,93 \pm 504,98$ & 689,13 & 2517,22 & $2300 \S$ \\
\hline
\end{tabular}

† Estimated Average Requirement (EAR), $\ddagger$ Adequate Intake (Al), $\S$ Tolerable Upper Intake Levels (UL)

All subjects had insufficient potassium intake. Calcium intake was inadequate in nine (100\%) men and $27(96.43 \%)$ women. Iron intake by $21(75.00 \%)$ women and $6(66.67 \%)$ men was adequate (Table 2$)$. Sodium was the most suitable mineral in the sample. Sodium intake was higher among men, and two $(22.22 \%)$ of them consumed above the tolerable limit $(2300 \mathrm{mg})$, while none of the women exceeded this value. There were no statistically significant differences in the adequacy of mineral intake according to sex (Table 2).

Table 2 Adequacy of mineral intake by hypertensive patients aged 80 years or more according to sex $(n=37)$

\begin{tabular}{lllll}
\hline Minerals & Usual intake & Women & Men & \multirow{2}{*}{$\mathbf{P}^{*}$} \\
\cline { 3 - 4 } & & $\mathbf{n}(\%)$ & $\mathbf{n}(\%)$ & \\
\hline Calcium & Adequate & $\mathrm{I}(3,57)$ & $0(0)$ & $\mathrm{I}, 000$ \\
& Inadequate & $27(96,43)$ & $9(100,00)$ & \\
Iron & Adequate & $2 \mathrm{I}(75,00)$ & $6(66,67)$ & 0,079 \\
& Inadequate & $7(25,00)$ & $3(33,33)$ & \\
\multirow{2}{*}{ Potassium*** } & Adequate & $0(0)$ & $0(0)$ & - \\
& Inadequate & $28(100,00)$ & $9(100,00)$ & \\
Sodium & Adequate & $28(100,00)$ & $7(77,78)$ & 0,054 \\
& Inadequate & $0(0)$ & $2(22,22)$ & \\
\hline
\end{tabular}

*p-value, Fisher's exact test. $* *$ It was not possible to perform the statistical test because all individuals had inadequate consumption

Most of the elderly had controlled blood pressure values. Among the 37 individuals, only eight (21.62\%) had uncontrolled SBP and only one $(2.70 \%)$ uncontrolled DBP. There was no association between adequacy of mineral intake and control of SBP and DBP (Table 3) (Table 4). The elderly had low level of schooling and income. Studies suggest that increased income results in increased intake of sodium, potassium, and calcium. Increased level of schooling contributes to an increase in the consumption of calcium, potassium and a decrease in sodium consumption..$^{10,24,25}$

The high prevalence of calcium intake inadequacy found in men $(100 \%)$ and women $(96.43 \%)$ in this sample approximated the values identified by Martini et al. ${ }^{25}$ ranging from $92 \%$ in elderly men to $99 \%$ in Women. Low calcium intake is due to insufficient consumption of dairy products, less than three servings per day. ${ }^{26,27}$ In 569 Australian women over 80 years, mean intake of 1.9 servings of dairy foods per day was identified, and only $49(8.7 \%)$ had 3 servings or more in the diet. ${ }^{28}$ In postmenopausal Italian women, the prevalence of osteoporosis and hypertension was higher among those who consumed the least amount of dairy products. Thus, low consumption of milks and derivatives was considered a risk factor for both diseases. ${ }^{29}$

Table 3 Adequacy of mineral intake by hypertensive patients aged 80 years or more according to systolic blood pressure control $(n=37)$

\begin{tabular}{lllll}
\hline \multicolumn{5}{c}{ SBP } \\
\hline Minerals & Usual intake & Controlled & High & $\mathbf{p}^{*}$ \\
\hline Calcium & Adequate & $\mathbf{n}(\%)$ & $\mathbf{n}(\%)$ & \\
& Inadequate & $29(100)$ & $7(87,5)$ & \\
Iron & Adequate & $2 \mathrm{I}(72,4 \mathrm{I})$ & $6(75)$ & $\mathrm{I}, 000$ \\
& Inadequate & $8(27,59)$ & $2(25)$ & \\
Potassium** & Adequate & $0(0)$ & $0(0)$ & - \\
& Inadequate & $29(100)$ & $8(100)$ & \\
Sodium & Adequate & $28(96,55)$ & $7(87,5)$ & 0,390 \\
& Inadequate & $\mathrm{I}(3,45)$ & $\mathrm{I}(12,5)$ & \\
\hline
\end{tabular}

*p-value, Fisher's exact test. **It was not possible to perform the statistical test because all individuals had inadequate consumption

Table 4 Adequacy of mineral intake by hypertensive patients aged 80 years or more according to diastolic blood pressure control $(n=37)$

\begin{tabular}{|c|c|c|c|c|}
\hline \multirow[b]{2}{*}{ Minerals } & \multirow[b]{2}{*}{ Usual intake } & \multicolumn{3}{|l|}{ DBP } \\
\hline & & Controlled & High & $\mathbf{p}^{*}$ \\
\hline & & n (\%) & n (\%) & \\
\hline \multirow[t]{2}{*}{ Calcium } & Adequate & I $(2,78)$ & $0(0)$ & 1,000 \\
\hline & Inadequate & $35(97,22)$ & I $(100)$ & \\
\hline \multirow[t]{2}{*}{ Iron } & Adequate & $27(75)$ & $0(0)$ & 0,270 \\
\hline & Inadequate & $9(25)$ & I (100) & \\
\hline \multirow[t]{2}{*}{ Potassium** } & Adequate & $0(0)$ & $0(0)$ & - \\
\hline & Inadequate & $36(100)$ & I $(100)$ & \\
\hline \multirow[t]{2}{*}{ Sodium } & Adequate & $34(94,44)$ & $I(100)$ & 1,000 \\
\hline & Inadequate & $2(5,56)$ & $0(0)$ & \\
\hline
\end{tabular}

*p-value, Fisher's exact test. **It was not possible to perform the statistical test because all individuals had inadequate consumption 
The present sample had an average calcium intake of $443,20 \mathrm{mg}$. Among Canadians aged 80 years and over, the mean was $817.2 \mathrm{mg},{ }^{30}$ higher than the present study, but still below the recommendation of $1200 \mathrm{mg} .{ }^{20}$ In the present sample there was no significant association between calcium intake and SBP or DBP values $(p>0.05)$. Ferreira ${ }^{14}$ associated low calcium intake with higher blood pressure and cardiovascular risk factors in Brazilian adult female research.

Gesmen-Karadag et al. ${ }^{15}$ classified Turkish elderly in the hypertensive, prehypertensive and normotensive groups. Lower calcium intake was significantly related to higher SBP values in the prehypertensive group $(\mathrm{p}=0.028)$.

The value of $100 \%$ of inadequacy for potassium intake in the sample studied is alarming, much higher than that observed in elderly people in Brazilian South. Mineral consumption was below the recommended level in $53.5 \%$ of those evaluated in the aforementioned study, but a food frequency questionnaire was used. ${ }^{31}$ The insufficient consumption of potassium reveals low diversification of the diet, with reduced presence of fruits and vegetables. Among Brazilians from Vitória - ES, considering all ages, $87.7 \%$ did not reach the recommended value of $4700 \mathrm{mg} /$ day. ${ }^{32}$ Potassium plays an essential role in normal cell function. Hypokalemia occurs when the blood concentration of the mineral is less than $3.5 \mathrm{mmol} / \mathrm{L}$ and may be a cause of cardiac arrhythmias, muscle weakness, and glucose intolerance. The individual with moderate potassium deficiency, in whom hypokalemia is not present, may suffer from increased SBP, altered bone metabolism, increased sensitivity to salt, increased risk of renal calculus and cardiovascular risk. ${ }^{13}$

In the present study it was not possible to evaluate the association between BP and potassium intake. In Americans over 20 years potassium consumption was significantly associated with SBP and DBP values. The increase of $1000 \mathrm{mg} / \mathrm{d}$ in potassium intake resulted in a reduction of $1.24 \mathrm{mmHg}$ in $\mathrm{SBP}(\mathrm{p}=0.001)$ and $0.75 \mathrm{mmHg}$ in DBP $(\mathrm{p}=0.007){ }^{33}$

Low potassium consumption is considered a risk factor for easily modifiable hypertension. Du et al. ${ }^{34}$ in the face of high salt intake and low potassium intake in Chinese adults, concluded that the substitution of sodium by potassium in salt could be efficient in reducing hypertension levels, along with other actions to prevent and control the disease. Zhao et al. ${ }^{35}$ also found similar results with Chinese over 40 years. In Brazilian elderly, it was verified that $80 \%$ of men and $61 \%$ of women had habitual excessive intake of sodium. ${ }^{6}$ In the study of elderly Turkish patients, it was observed higher sodium consumption in the hypertensive group compared to prehypertensive and normotensive patients $(\mathrm{p}<0.05)$. Higher sodium intake $(\mathrm{p}=0.04)$ and sodium-potassium ratio $(\mathrm{p}=0.03)$ were directly associated with increased SBP in hypertensive patients. ${ }^{15}$

Still in the present study, no significant association between sodium intake and SBP or DBP values was identified. Perin et al. ${ }^{10}$ when evaluating elderly hypertensives, observed that high levels of SBP were associated with less salt addition to meals, perhaps due to the perception of disease severity. In the present sample, few subjects $(n=2)$ exceeded UL for sodium, probably because the participants in this study undergo ambulatory follow-up for Hypertension, in which they receive guidelines for disease control, including dietary counseling such as reduction of addition salt.

According to Giroto et al.$^{36}$ the majority of elderly hypertensive patients studied $(69.1 \%)$ reported some dietary changes to control blood pressure. Among these, there was a reduction in the consumption of foods considered at risk, and the restrictions on salt, fat and sweets consumption were among the most mentioned. These results lead to the perception that individuals relate the control of hypertension to the reduction of the intake of risky foods and not to the consumption of foods such as fruits and vegetables.

Among those evaluated by the present study, $27.03 \%$ did not reach the recommendation of iron intake. Fisberg et al. ${ }^{6}$ found a prevalence of low iron consumption less than $15 \%$ in Brazilian elderly. In the present sample, mean iron intake was $7.21 \mathrm{mg}$, lower than that found in Canadians aged 80 years or older, where the mean was $9.8 \mathrm{mg}{ }^{30}$

Among the elderly in Porto Alegre, the amount of some minerals in the diet seemed to be influenced by the presence of chronic diseases. There was lower iron consumption among hypertensive patients $(\mathrm{p}=0.005) .{ }^{24}$ In hypertensive and diabetic patients analyzed by Souza et al. ${ }^{37}$ it was observed that almost all subjects $(92.8 \%)$ were regularly consuming red meat, but $57.8 \%$ reported their reduction as dietary care. Reducing the consumption of red meat by hypertensive patients as a control step for fat and sodium intake may result in lower iron intake.

A higher prevalence of dementia among elderly people with iron deficiency was observed at a geriatric clinic in Turkey, even before the level of anemia was reached $(p=0.037)$. Iron has an essential role in the storage and transport of oxygen, so its deficiency may be responsible for the occurrence of cerebral hypoxia and decreased cognitive abilities. ${ }^{18}$ Kirkpatrick et al. ${ }^{19}$ found a relationship between cognitive decline and lower medication adherence $(\mathrm{p}<0.001)$ with a tendency towards lower antihypertensive use $(\mathrm{p}=0.06)$. Despite the adequate consumption of iron by most subjects, the follow-up of their intake should be continuous among the elderly, given the possible health problems due to mineral deficiency.

Among the individuals evaluated by the present study, only 8 $(21.62 \%)$ presented uncontrolled SBP and 1 (2.70\%) uncontrolled DBP, which suggests the treatment offered by this public reference center is efficient. The high number of subjects with controlled BP resembled results found in developed countries, such as the United States, England and Canada, where $75 \%$ of women and $71 \%$ of hypertensive men, of all ages, achieved satisfactory rates of control. ${ }^{38}$ The small size of the sample and the lack of studies investigating the consumption of minerals in a similar population limited the conclusions of this study.

\section{Conclusion}

In summary, a low intake of calcium and potassium was identified among those evaluated, and none of the individuals reached the recommended value for potassium. Most of the elderly had adequate iron intake and few exceeded the tolerable limit of sodium intake. The results found should be considered in the planning of actions to encourage healthy eating with adequate presence of minerals and public policies that guarantee access to these foods.

\section{Acknowledgements}

None.

\section{Conflict of interest}

Authors declare there is no conflict of interest in publishing the article. 


\section{References}

1. http://www.ibge.gov.br/apps/populacao/projecao/

2. http://www.ibge.gov.br/home/estatistica/populacao $\% 20 /$ indic_ sociosaude/2009/default.shtm

3. http://censo2010.ibge.gov.br/sinopse/webservice/

4. World Health Organization. World Aging and Health Report. Geneve: World Health Organization, Switzerland; 2015.

5. Ministry of Health. National Food and Nutrition Policy. Brazil; 2012.

6. Fisberg RM, Marchioni DML, Castro MA, et al. Inadequate intake of nutrients in the elderly population of Brazil: National food survey 20082009. Rev Saude Publ. 2013;47(1):222-230.

7. Ministry of Health. Food guide for the Brazilian population: promoting healthy eating. Brazil; 2008.

8. Brazilian Institute of Geography and Statistics. Search for Family Budgets - POF 2008-2009. Analysis of personal food consumption in Brazil. Rio de Janeiro, Brazil; 2011.

9. Christopher PH, Eileen TK, Abraham H. Institute of Medicine Prevention of Micronutrient Deficiencies: Tools for Policymakers and Public Health Workers. The National Academie Press, Whashington, USA; 1998.

10. Perin MS, Cornélio ME, Rodrigues RCM, et al. Characterization of salt consumption among hypertensive patients according to sociodemographic and clinical factors. Rev Lat Am Enfermagem. 2013;21(5):1-9.

11. Esperandio EM, Espinosa MM, Martins MSA, et al. Prevalence and factors associated with arterial hypertension in the elderly in municipalities of the Legal Amazon, MT Rev Bras Geriatr Gerontol. 2013;16(3):481-493.

12. Tavares DMS, Guimarães MO, Ferreira PCS, et al. Quality of life and accession to the pharmacological treatment among elderly hypertensive. Rev Bras Enferm. 2015;68(1):122-129.

13. Institute of Medicine. Dietary Reference Intakes for Water, Potassium, Sodium, Chloride and Sulfate. The National Academie Press, Washington, USA; 2005 .

14. Ferreira TS, Torres MRSG, Sanjuliani AF. Dietary calcium intake is associated with adiposity, metabolic profile, inflammatory state and blood pressure, but not with erythrocyte intracellular calcium and endothelial function in healthy pre-menopausal women. $\mathrm{Br} J \mathrm{Nutr}$. 2013;110(6):1079-1088

15. Karadag GM, Bilici S, Nilufer AT, et al. Relationship between dietary mineral intake and blood pressure (BP) in the elderly in Turkey. Arch of Gerontol Geriatr. 2012;55(1):106-111.

16. Ministry of Health. National Supplementary Health Agency. Plan of care for the elderly in supplementary health. Rio de Janeir, Brazil; 2013.

17. Brazilian Institute of Geography and Statistics. Perception of health status, lifestyles and chronic diseases. Brazil major regions and federation units, Brazil; 2013.

18. Yavus BB, Cankurtaran M, Haznedaroglu IC, et al. Iron deficiency can cause cognitive impairment in geriatric patients. $J$ Nutr Health Aging. 2012;16(3):220-224

19. Kirkpatrick AC, Vicent AS, Guthery L, et al. Cognitive impairment is associated with medication nonadherence in asymptomatic carotid stenosis. Am J Med. 2014;127(12):1243-1246.

20. Institute of Medicine. Dietary Reference Intakes for Calcium and Vitamin $D$. The National Academie Press, Washington, USA; 2011.

21. Institute of Medicine. Dietary Reference Intakes for Vitamin A, Vitamin K, Arsenic, Boron, Chromium, Copper, Iodine, Iron, Manganese, Molybdenum, Nickel, Silicon, Vanadium, and Zinc. The National Academie Press, Washington, USA; 2005.
22. Brazilian Society of Cardiology. Brazilian Society of Hypertension Brazilian Society of Nephrology. VI Brazilian Guidelines on Hypertension. Arq Bras Cardiol. 2010;95(1):1-51.

23. Weber MA, Schiffrin EL, White WB, et al. Clinical Practice Guidelines for the Management of Hypertension in the Community: A Statement by the American Society of Hypertension and the International Society of Hypertension. J Clin Hypertens. 2014;32(1):3-15.

24. Venturine CD, Engroff P, Sgnaolin V, et al. Nutrient intake in elderly residents in Porto Alegre, Brazil: a population-based study. Cien Saude Colet. 2015;20:3701-3711.

25. Martini LA, Verly E, Marchioni DML, et al. Prevalence and correlates of calcium and vitamin D status adequacy in adolescents, adults and elderly from the Health Survey-São Paulo Nutrition. 2013;29(6):845-850.

26. Lima RSS, Lima RS, Almeida ASSS. Health project: food and nutritiona profile of elderly women from a municipality in the interior of Ceará. RBNE. 2013;7(37):4-12.

27. Leite SC, Baratto I, Silva R. Calcium intake and risk of osteoporosis in an elderly population. RBONE. 2014;8(48):165-174.

28. Bagatini RS, Zhu K, Lewis JR, et al. Dairy food intake, peripheral bone structure and muscle mass in elderly ambulatory women. J Bone Miner Res. 2014;29(7):1691-1700.

29. Varenna M, Manara M, Gall L, et al. The association between osteoporosis and hypertension: the role of a low dairy intake. Calcif Tissue Int. 2013;93(1):86-92.

30. Redondo JSB, Miguel BB, Banega JG, et al. Influence of nutritional status on health-related quality of life of non-institutionalized older people. J Nutr Health Aging. 2014;18(4):359-369.

31. Dourado CM. Bone mineral density in the elderly and presence of nutritional risk factors for osteoporosis. Porto Alegre: Pontifical Catholic University of Rio Grande do Sul, Brasil; 2012.

32. Rodrigues SL, Baldo MP, Machado RC, et al. High potassium intake blunts the effect of elevated sodium intake on blood pressure levels. $J \mathrm{Am}$ Soc Hypertens. 2014;8(4):232-238.

33. Zhang Z, Cogswell ME, Gillespie C, et al. Association between Usua Sodium and Potassium Intake and Blood Pressure and Hypertension among U.S. Adults: NHANES 2005-2010. Plos One. 2013;8(10):1-10.

34. Du S, Batis AN, Wang H, et al. Understanding the patterns and trends of sodium intake, potassium intake, and sodium to potassium ratio and their effect on hypertension in China. Am J Clin Nutr. 2014;99(2):334-343.

35. Zhao X, Yin X, Li X, et al. Using a Low-Sodium, High-Potassium Salt Substitute to Reduce Blood Pressure among Tibetans with High Blood Pressure: A Patient-Blinded Randomized Controlled Trial. Plos One. 2014;9(10):1-8.

36. Giroto E, Andrade SM, Cabrera MAS, et al. Adherence to pharmacological and non-pharmacological treatment and associated factors in the primary care of hypertension. Cienc Saude Colet. 2013;18(6):1763-1772.

37. Sousa BRM, Vieira DPB, Silva IRP, et al. Nutrition profile of users of the HIPERDIA Program in Ananindeua, Pará, Brazil. Rev Bras Med Fam. 2013;8(28):187-195.

38. Joffres M, Falaschetti E, Gillespie C, et al. Hypertension prevalence, awareness, treatment and control in national surveys from England, the USA and Canada, and correlation with stroke and ischaemic heart disease mortality: a cross-sectional study. BMJ Open. 2013;3(8):e003423. 